\title{
A Novel Method for Interval-Value Intuitionistic Fuzzy Multicriteria Decision-Making Problems with Immediate Probabilities Based on OWA Distance Operators
}

\author{
Ya Qin $\mathbb{D}^{1,2}$ Yi Liu ${ }^{1},{ }^{1}$ and Jun Liu ${ }^{3}$ \\ ${ }^{1}$ Data Recovery Key Laboratory of Sichuan Province, Neijiang Normal University, Neijiang, Sichuan 641000, China \\ ${ }^{2}$ School of Mathematics and Information, Neijiang Normal University, Neijiang, Sichuan 641000, China \\ ${ }^{3}$ School of Computing, Ulster University, Jordanstown Campus, UK \\ Correspondence should be addressed to Yi Liu; liuyiyl@126.com
}

Received 17 December 2017; Revised 1 June 2018; Accepted 19 June 2018; Published 5 July 2018

Academic Editor: Peide Liu

Copyright (C) 2018 Ya Qin et al. This is an open access article distributed under the Creative Commons Attribution License, which permits unrestricted use, distribution, and reproduction in any medium, provided the original work is properly cited.

\begin{abstract}
The goal of this work is to develop a novel decision-making method which can solve some complex decision problems that include the following three-aspect information: (1) information represented in the form of interval-valued intuitionistic fuzzy values (IVIFVs) not only intuitionistic fuzzy values (IFVs), (2) the probability information and the weighted information, and (3) the importance degree of each concept in the process of decision-making. Firstly, by integrating OWA operator, probabilistic weight (PW), and individual distance of two IVIFNs in the same formulation, we introduce two new distance operators named PIVIFOWAD operator and IPIVIFOWAD operator, respectively. Secondly, satisfaction degree of an alternative is proposed based on the positive ideal IVIFS and the negative ideal IVIFS and applied to MCDM. Finally, we use an illustrative example to show the feasibility and validity of the new method by comparing with the other existing methods.
\end{abstract}

\section{Introduction}

Atanassov and Gargov [1, 2] introduced the theory of Interval-Valued Intuitionistic Fuzzy Set (IVIFS), which is a generalization of the Intuitionistic Fuzzy Set (IFS) proposed by Atanassov [3]. The IVIFS has attracted more and more attention since its appearance. Some decision-making methods under IVIF environment have been developed by many scholars. To sum up, there are mainly four aspects on the decision-making under IVIF environment: (1) some decision-making methods are developed based on information measures (specially, distance, similarity, and entropy) because information measures for IVIFSs have great effects on the development of the IVIFS theory and its applications. For example, similarity measures [4-6], inclusion measure [7], entropy measure [8], cross-entropy measure [9], and distance measures [10] are developed and applied to corresponding MCDM and MADM problems; (2) many new aggregation operators are also investigated in the IVIFSs and applied to some decision-making problems, such as linguistic intuitionistic fuzzy power Bonferroni Mean operators [11], Hamacher aggregation operators [12], fuzzy power Heronian aggregation operators [13], fuzzy generalized aggregation operator [11, 14-18], (fuzzy Einstein) hybrid weighted aggregation operators $[19,20]$, fuzzy prioritized hybrid weighted aggregation operator [21], and fuzzy Hamacher ordered weighted geometric operator [22]; (3) other methods for decisionmaking with IVIF information are also explored, such as evidential reasoning methodology [23], particle swarm optimization techniques [4], transform technique [24], nonlinear programming methods [25], and VIKOR methods in IVIFS [26], and others methods [27-32] are also developed for decision-making problems. Distance measure has great effects on obtaining the desirable choice in some decision problems. Motivated by the OWA operator, Xu [33] introduced ordered weighted distance operator based on known Haming distance. Many extensions of distance operator have been developed; for example, Merigo et al. [34] introduced 
a series of aggregation operators related to distance measures [35-38] which were applied to related decision problems $[37,39,40]$.

In some real decision problems, many problems are very complex. Aiming at solving some of these complicated decision problems, it is necessary to develop a new kind of decision-making method to solve this kind of problems including the following three-aspect information: (1) information represented in the form of IVIFVs not only IFVs, (2) the weighted information and the probability information, and (3) the degree of importance of each concept in the process of decision-making. Motivated by the ideas of existing operators, we propose new IVIF distance measures by using related weighted operators with probabilistic information and their applications in MCDM in the present work.

The rest of the paper is organized as follows. In Section 2, we review some related definitions on IVIFSs which are in the analysis throughout this paper. Section 3 is focused on PIVPFOWAD and IPIVIFOWAD. In Section 4, the concept of satisfaction degree is proposed and the MCDM approach based on the satisfaction degree is also constructed. Section 5, a practical example, is given to explain proposed method and compare and analyze the availability of proposed MCDM methods. This paper is concluded in Section 6.

\section{IVIFSs and OWA Distance Operator}

In this section, some related basic concepts of VIFSs, OWA operator, and OWAD operator are recapped.

2.1. Interval-Valued Intuitionistic Fuzzy Sets. Assume that $\operatorname{int}([0,1])$ is the collection of all closed subintervals of $[0,1]$, and $X$ is a universe of discourse. An IVIFS $[1,2]$ on $X$ has such a structure

$$
\widetilde{A}=\left\{\left\langle x,\left(\mu_{\widetilde{A}}(x), \nu_{\widetilde{A}}(x)\right)\right\rangle \mid x \in X\right\} .
$$

where $\mu_{\widetilde{A}}: X \longrightarrow \operatorname{int}([0,1])$ denotes the membership degree and $v_{\widetilde{A}}: X \longrightarrow \operatorname{int}([0,1])$ denotes the nonmembership degree of the element $x \in X$ to the set $\widetilde{A}$, respectively, with the condition that $0 \leq \sup \left(\mu_{\widetilde{A}}(x)\right)+\sup \left(\nu_{\widetilde{A}}(x)\right) \leq 1$.

For each $x \in X, \mu_{\widetilde{A}}(x)$ and $\nu_{\widetilde{A}}(x)$ denote $\mu_{\widetilde{A}}(x)=$ $\left[\mu_{\widetilde{A}}^{-}(x), \mu_{\widetilde{A}}^{+}(x)\right], \nu_{\widetilde{A}}(x)=\left[\nu_{\widetilde{A}}^{-}(x), \nu_{\widetilde{A}}^{+}(x)\right]$, respectively. Therefore, $\widetilde{A}$ may be also expressed as

$$
\begin{aligned}
\widetilde{A} & =\left\{\left\langle x,\left(\left[\mu_{\widetilde{A}}^{-}(x), \mu_{\widetilde{A}}^{+}(x)\right],\left[\nu_{\widetilde{A}}^{-}(x), \nu_{\widetilde{A}}^{+}(x)\right]\right)\right\rangle \mid x\right. \\
& \in X\} .
\end{aligned}
$$

Eq. (2) satisfies the condition $\mu_{\widetilde{A}}^{+}(x)+\nu_{\widetilde{A}}^{+}(x) \leq 1$.

$$
\begin{aligned}
& \pi_{\widetilde{A}}(x)=\left[\pi_{\widetilde{A}}^{-}(x), \pi_{\widetilde{A}}^{+}(x)\right] \\
& \quad=\left[1-\left(\mu_{\widetilde{A}}^{+}(x)\right)-\left(\nu_{\widetilde{A}}^{+}(x)\right), 1-\left(\mu_{\widetilde{A}}^{-}(x)\right)-\left(\nu_{\widetilde{A}}^{-}(x)\right)\right]
\end{aligned}
$$

is called the indeterminacy degree. For the convenience, $\widetilde{A}=$ $\left(\left[\mu_{\widetilde{A}}^{-}, \mu_{\widetilde{A}}^{+}\right],\left[\nu_{\widetilde{A}}^{-}, \nu_{\widetilde{A}}^{+}\right]\right)$is called an interval-valued intuitionistic fuzzy value (IVIFV).
Hereafter, $\mathscr{I} \mathscr{V} \mathscr{I F} \mathscr{F}$ denotes the collection of all IVIFVs of a IVIFS on $X$.

For two IVIFVs $\widetilde{A}_{1}=\left(\left[\mu_{\widetilde{A}_{1}}^{-}, \mu_{\widetilde{A}_{1}}^{+}\right],\left[\nu_{\widetilde{A}_{1}}^{-}, \nu_{\widetilde{A}_{1}}^{+}\right]\right)$and $\widetilde{A}_{2}=$ $\left(\left[\mu_{\widetilde{A}_{2}}^{-}, \mu_{\widetilde{A}_{2}}^{+}\right],\left[\nu_{\widetilde{A}_{2}}^{-}, \nu_{\widetilde{A}_{2}}^{+}\right]\right)$, a relation $\leq$on the IVIFVs is defined as follows:

$$
\begin{aligned}
\mu_{\widetilde{A}_{1}}^{-} & \leq \mu_{\widetilde{A}_{2}}^{-}, \\
\mu_{\widetilde{A}_{1}}^{+} & \leq \mu_{\widetilde{A}_{2}}^{+} \\
\text {and } \nu_{\widetilde{A}_{1}}^{-} & \geq \nu_{\widetilde{A}_{2}}^{-}, \\
v_{\widetilde{A}_{1}}^{+} & \geq v_{\widetilde{A}_{2}}^{+} .
\end{aligned}
$$

In order to compare two IVIFVs, score function and accuracy function [41] of an IVIFV are introduced.

For any IVIFV $\widetilde{A}=\left(\left[\mu_{\widetilde{A}}^{-}, \mu_{\widetilde{A}}^{+}\right],\left[\nu_{\widetilde{A}}^{-}, \nu_{\widetilde{A}}^{+}\right]\right)$, the score function $\widetilde{\boldsymbol{s}}(\widetilde{A})$ of $\widetilde{A}$ is defined as follows:

$$
\widetilde{s}(\widetilde{A})=\frac{1}{2}\left(\left(\mu_{\widetilde{A}}^{-}\right)+\left(\mu_{\widetilde{A}}^{+}\right)-\left(\nu_{\widetilde{A}}^{-}\right)-\left(\nu_{\widetilde{A}}^{+}\right)\right),
$$

where $\widetilde{s}(\widetilde{A}) \in[-1,1]$.

For any IVIFV $\widetilde{A}=\left(\left[\mu_{\widetilde{A}}^{-}, \mu_{\widetilde{A}}^{+}\right],\left[\nu_{\widetilde{A}}^{-}, \nu_{\widetilde{A}}^{+}\right]\right)$, the accuracy function $\widetilde{a}(\widetilde{A})$ of $\widetilde{A}$ is defined as follows:

$$
\widetilde{a}(\widetilde{A})=\frac{1}{2}\left(\left(\mu_{\widetilde{A}}^{-}\right)+\left(\mu_{\widetilde{A}}^{+}\right)+\left(\nu_{\widetilde{A}}^{-}\right)+\left(\nu_{\widetilde{A}}^{+}\right)\right),
$$

where $\widetilde{s}(\widetilde{A}) \in[0,1]$.

Based on the above definitions, comparison rules are defined as follows.

For any two IVIFVs $\widetilde{A}_{1}, \widetilde{A}_{2}$,

(1) if $\widetilde{\mathcal{S}}\left(\widetilde{A}_{1}\right)<\widetilde{\mathcal{s}}\left(\widetilde{A}_{2}\right)$, then $\widetilde{A}_{1} \prec \widetilde{A}_{2}$;

(2) if $\widetilde{s}\left(\widetilde{A_{1}}\right)=\widetilde{s}\left(\widetilde{A}_{2}\right)$, then

$$
\begin{aligned}
& \text { (a) if } \widetilde{a}\left(\widetilde{A}_{1}\right)<\widetilde{a}\left(\widetilde{A}_{2}\right) \text {, then } \widetilde{A}_{1} \prec \widetilde{A}_{2} \text {; } \\
& \text { (b) if } \widetilde{a}\left(\widetilde{A}_{1}\right)=\widetilde{a}\left(\widetilde{A}_{2}\right) \text {, then } \widetilde{A}_{1} \sim \widetilde{A}_{2} .
\end{aligned}
$$

2.2. OWA Distance Operator. In this section, we will review the OWAD operator and then introduce IVIFOWAD operator.

An OWA operator [42] is a function OWA : $R^{n} \longrightarrow R$ that has an associated weight vector $(\mathrm{WV}) \omega=\left(\omega_{1}, \ldots, \omega_{n}\right)$ with $\omega_{j} \in[0,1]$ and $\sum_{j=1}^{n} \omega_{j}=1$, such that

$$
\operatorname{OWA}\left(a_{1}, O_{2}, \ldots, a_{n}\right)=\sum_{j=1}^{n} \omega_{j} b_{j}
$$

where $\left(a_{1}, \ldots, a_{n}\right) \in R^{n}$ and $b_{j}$ is the $j$ th largest of $a_{i}$.

Similarly, OWAD operator is introduced as a generalization of OWA operator. Let $A=\left(a_{1}, \ldots, a_{n}\right), B=\left(b_{1}, \ldots, b_{n}\right)$ be two collections of arguments. An OWAD operator [36] is a function $O W A D: R^{n} \times R^{n} \longrightarrow R$ that has an associated $\mathrm{WV}$ $\omega=\left(\omega_{1}, \ldots, \omega_{n}\right)$ with $\omega_{j} \in[0,1]$ and $\sum_{j=1}^{n} \omega_{j}=1$, such that

$$
\operatorname{OWAD}(A, B)=\sum_{j=1}^{n} \omega_{j} d_{j}
$$

where $d_{j}$ is the $j$ th largest of $\left|a_{i}-b_{i}\right|$. 
Let $\widetilde{A}=\left\{\widetilde{a}_{i}=\left(\mu_{\widetilde{a}_{i}}, v_{\widetilde{a}_{i}}\right)\right\}$ and $\widetilde{B}=\left\{\widetilde{b}_{i}=\left(\mu_{\tilde{b}_{i}}, v_{\tilde{b}_{i}}\right)\right\}$ be two collections of IVIFVs, where $\left(\mu_{\widetilde{a}_{i}}, v_{\widetilde{a}_{i}}\right)=\left(\left[\mu_{\widetilde{a}_{i}^{-}}, \mu_{\widetilde{a}_{i}^{+}}\right],\left[\nu_{\widetilde{a}_{i}}^{-}, v_{\widetilde{a}_{i}}^{+}\right]\right)$, $\left(\mu_{\tilde{b}_{i}}, v_{\tilde{b}_{i}}\right)=\left(\left[\mu_{\tilde{b}_{i}}^{-}, \mu_{\tilde{b}_{i}}^{+}\right],\left[\nu_{\tilde{b}_{i}}^{-}, v_{\tilde{b}_{i}}^{+}\right]\right)$, and $i=1, \ldots, n$. We first recall the distance [10] between two IVIFVs $\widetilde{a}_{1}=\left(\left[\mu_{\widetilde{a}_{1}}^{-}, \mu_{\widetilde{a}_{1}}^{+}\right]\right.$, $\left.\left[\nu_{\tilde{a}_{1}}^{-}, \nu_{\tilde{a}_{1}}^{+}\right]\right)$and $\widetilde{a}_{2}=\left(\left[\mu_{\tilde{a}_{2}}^{-}, \mu_{\tilde{a}_{2}}^{+}\right],\left[\nu_{\tilde{a}_{2}}^{-}, \nu_{\tilde{a}_{2}}^{+}\right]\right)$.

$$
\begin{aligned}
& d\left(\widetilde{a}_{1}, \widetilde{a}_{2}\right)=\frac{1}{4}\left(\left|\left(\mu_{\tilde{a}_{1}}^{-}\right)-\left(\mu_{\tilde{a}_{2}}^{-}\right)\right|+\left|\left(\mu_{\widetilde{a}_{1}}^{+}\right)-\left(\mu_{\tilde{a}_{2}}^{+}\right)\right|\right. \\
& \quad+\left|\left(\nu_{\tilde{a}_{1}}^{-}\right)-\left(\nu_{\tilde{a}_{2}}^{-}\right)\right|+\left|\left(v_{\tilde{a}_{1}}^{+}\right)-\left(v_{\tilde{a}_{2}}^{+}\right)\right|+\left|\left(\pi_{\tilde{a}_{1}}^{-}\right)-\left(\pi_{\tilde{a}_{2}}^{-}\right)\right| \\
& \left.\quad+\left|\left(\pi_{\tilde{a}_{1}}^{+}\right)-\left(\pi_{\tilde{a}_{2}}^{+}\right)\right|\right) .
\end{aligned}
$$

\section{IPIVIFOWA Distance Operator}

In this subsection, by combining OWA operator, individual distances, and PWs, two new distances named PIVIFOWAD operator and IPIVIFOWAD operator will be introduced. PIVIFOWAD operator is defined as follows.

Definition 1. A PIVIFOWAD is a function PIVIFOWAD: $\mathscr{I V} \mathscr{I} \mathscr{F} \mathscr{V}^{n} \times \mathscr{I V} \mathscr{I} \mathscr{F} \mathscr{V}^{n} \longrightarrow \mathbf{R}$, that has an associated WV $\omega=\left(\omega_{1}, \omega_{2}, \ldots, \omega_{n}\right)^{T}$ with $\omega_{i}>0, \sum_{i=1}^{n} \omega_{i}=1(i=1,2, \ldots, n)$, such that

$$
\begin{aligned}
\operatorname{PIVIFOWAD}(\widetilde{A}, \widetilde{B})= & \xi \sum_{i=1}^{n} \omega_{i} d\left(\widetilde{a}_{i}, \widetilde{b}_{i}\right) \\
& +(1-\xi) \sum_{j=1}^{n} p_{j} d\left(\widetilde{a}_{j}, \widetilde{b}_{j}\right)
\end{aligned}
$$

where $d\left(\widetilde{a}_{i}, \widetilde{b}_{i}\right)$ is the $i$ th largest of $d\left(\widetilde{a}_{j}, \widetilde{b}_{j}\right)$ and each $d\left(\widetilde{a}_{j}, \widetilde{b}_{j}\right)$ has associated a probabilistic $p_{j} \in[0,1], \sum_{i=j}^{n} p_{i}=1$.

In Definition 1 , if $\xi=1$, it will be reduced to intervalvalued intuitionistic fuzzy ordered weighted distant (IVIFOWAD) operator:

$$
\operatorname{IVIFOWAD}(\widetilde{A}, \widetilde{B})=\sum_{i=j}^{n} \omega_{j} d\left(\widetilde{a}_{j}, \widetilde{b}_{j}\right),
$$

where $d\left(\tilde{a}_{j}, \tilde{b}_{j}\right)$ is the $j$ th largest of $d\left(\tilde{a}_{i}, \tilde{b}_{i}\right)$ and $d\left(\tilde{a}_{i}, \tilde{b}_{i}\right)$ is the argument variable represented in the form of individual distance between IVIFVs $\tilde{a}_{i}, \widetilde{b}_{i}$.

Example 2. Let

$$
\begin{gathered}
\widetilde{A}=\{([0.3,0.7],[0.2,0.3]),([0.7,0.8],[0.1,0.2]), \\
([0.2,0.3],[0.5,0.6]),([0.5,0.6],[0.3,0.4])\}, \\
\widetilde{B}=\{([0.4,0.5],[0.2,0.4]),([0.5,0.6],[0.2,0.3]), \\
([0.2,0.4],[0.5,0.6]),([0.4,0.7],[0.2,0.3])\}
\end{gathered}
$$

be two collections of IVIFVs on the set $X=\left\{x_{1}, x_{2}, x_{3}, x_{4}\right\}$ and the $\mathrm{WV}$ is $\omega=(0.2,0.3,0.1,0.4)$. Take $\xi=0.3$; according to Definition 1 , we have

$$
\begin{aligned}
& \text { PIVIFOWAD }(\widetilde{A}, \widetilde{B})=0.3 \times(0.2 \times 0.2+0.3 \times 0.175 \\
& \quad+0.1 \times 0.175+0.4 \times 0.05)+0.7 \times(0.3 \times 0.175 \\
& \quad+0.2 \times 0.2+0.4 \times 0.05+0.1 \times 0.175)=0.13
\end{aligned}
$$

Now, we can also develop the IPIVIFOWAD operator by applying IVIF information, individual distance, and immediate probability (IP) [43].

Definition 3. An IPIVIFOWAD is a function IPIVIFOWAD : $\mathscr{I} \mathscr{V} \mathscr{I} \mathscr{F} \mathscr{V}^{n} \times \mathscr{I} \mathscr{V} \mathscr{I} \mathscr{F} \mathscr{V}^{n} \longrightarrow \mathbf{R}$ which has an associated $\mathrm{WV} \omega=\left(\omega_{1}, \omega_{2}, \ldots, \omega_{n}\right)^{T}$ with $\omega_{i}>0, \sum_{i=1}^{n} \omega_{i}=1(i=$ $1,2, \ldots, n)$, such that

$$
\operatorname{IPIVIFOWAD}(\widetilde{A}, \widetilde{B})=\sum_{i=1}^{n} \widehat{\rho_{i}} d\left(a_{i}, b_{i}\right),
$$

where $d\left(\widetilde{a}_{i}, \widetilde{b}_{i}\right)$ is the $i$ th largest of $d\left(\widetilde{a}_{j}, \widetilde{b}_{j}\right)$ and $d\left(\widetilde{a}_{j}, \widetilde{b}_{j}\right)$ is the argument variable represented in the form of individual distance between IVIFVs $\widetilde{a}_{i}, \widetilde{b}_{i}$ and a PW $p_{i}>0, \sum_{i=1}^{n} p_{i}=1$. $\widehat{\rho_{i}}=\omega_{i} p_{i} / \sum_{i=1}^{n} \omega_{i} p_{i}$ and $p_{i}$ is the probabilistic $p_{j}$ according to $d\left(\widetilde{a}_{i}, \widetilde{b}_{i}\right)$, that is, according to the $i$ th largest of the $d\left(\widetilde{a}_{i}, \widetilde{b}_{i}\right)$.

It is worth pointing out that IPIVIFOWAD operator is a good approach for unifying probabilities and IVIFOWAD in some particular situations. But it is not always useful. In order to show why this unification does not seem to be a final model, we could also consider other ways of representing $\widehat{p}_{i}$ as in [40].

Example 4. In Example 2, since the following $\mathrm{WV} \omega=$ $(0.2,0.3,0.1,0.4)$ and the PW $(0.3,0.2,0.4,0.1)$, now we aggregate this information according to IPIVIFOWAD, as we have calculated $d\left(a_{i}, b_{i}\right)$ by employing (7) as follows:

$$
\begin{aligned}
& d\left(a_{1}, b_{1}\right)=0.175, \\
& d\left(a_{2}, b_{2}\right)=0.2, \\
& d\left(a_{3}, b_{3}\right)=0.05, \\
& d\left(a_{4}, b_{4}\right)=0.175 .
\end{aligned}
$$

According to the above distance, we reorder the PW $(0.2,0.3,0.1,0.4)$,

$$
\sum_{i=1}^{5} \omega_{i} p_{i}=(0.2,0.3,0.1,0.4)(0.2,0.3,0.1,0.4)^{T}=0.3 .
$$

Therefore, $\widehat{\rho_{1}}=\omega_{1} p_{1} / \sum_{i=1}^{5} \omega_{i} p_{i}=(0.2 \times 0.2) / 0.3=0.133$, and similarly, we have $\widehat{\rho_{2}}=0.3, \widehat{\rho_{3}}=0.033, \widehat{\rho_{4}}=0.534$. Therefore, we have

$$
\begin{aligned}
& \operatorname{IPIVIFOWAD}(\widetilde{A}, \widetilde{B}) \\
& =0.133 \times 0.2+0.3 \times 0.175+0.033 \times 0.175 \\
& \quad+0.534 \times 0.05=0.112 .
\end{aligned}
$$

Monotonicity is a kind of vital property in the research of aggregation operators. The aggregation operator with monotonicity will be more reliable in decision-making process. The lack of monotonicity may depress the reliability of the final 
results. PIVIFOWAD and IPIVIFOWAD are new distance measure and are aggregation operators. We can prove that PIVIFOWAD and IPIVIFOWAD have the properties of boundness, monotonicity, and reflexivity. The proof of these properties is similar to Theorems 1-3 in [44].

\section{Method for MCDM Based on IPIVIFOWA Operator}

4.1. Formal Description of MCDM with IVIFs. The MCDM with IVIF information can be formally presented as follows.
Assume that $X=\left\{x_{1}, \ldots, x_{m}\right\}$ is a set of $m$ alternatives, $C=\left\{G_{1}, \ldots, C_{n}\right\}$ is the collection of attributes, and $\omega=$ $\left(\omega_{1}, \ldots, \omega_{n}\right)^{T}$ are the WV of all attributes, which satisfy $0 \leq$ $\omega_{i} \leq 1$. Assume that alternative $O_{i}(i=1, \ldots, m)$ with respect to attribute $C_{j}(j=1, \ldots, n)$ is evaluated by an IVIFVs $C_{j}\left(x_{i}\right)=\left(\left[\mu_{i j}^{-}, \mu_{i j}^{+}\right],\left[v_{i j}^{-}, v_{i j}^{+}\right]\right)(j=1,2, \ldots, n ; i=, 2, \ldots, m)$ and $R_{m \times n}=\left(C_{j}\left(x_{i}\right)\right)_{m \times n}$ is an IVIF decision matrix. A new kind MCDM approach will be developed based on the distance operators proposed in Section 3.

For a MCDM problem with IVIFVs, the decision matrix $R=\left(C_{j}\left(x_{i}\right)\right)_{m \times n}$ and can be constructed or given in advance.

$$
R_{m \times n}=\left(\begin{array}{cccc}
\left(\left[\mu_{11}^{-}, \mu_{11}^{+}\right],\left[v_{11}^{-}, v_{11}^{+}\right]\right) & \left(\left[\mu_{12}^{-}, \mu_{12}^{+}\right],\left[v_{12}^{-}, v_{12}^{+}\right]\right) & \cdots & \left(\left[\mu_{1 n}^{-}, \mu_{1 n}^{+}\right],\left[v_{1 n}^{-}, v_{1 n}^{+}\right]\right) \\
\left(\left[\mu_{21}^{-}, \mu_{21}^{+}\right],\left[v_{21}^{-}, v_{21}^{+}\right]\right) & \left(\left[\mu_{22}^{-}, \mu_{22}^{+}\right],\left[v_{22}^{-}, v_{22}^{+}\right]\right) & \cdots & \left(\left[\mu_{2 n}^{-}, \mu_{2 n}^{+}\right],\left[v_{2 n}^{-}, v_{2 n}^{+}\right]\right) \\
\vdots & \vdots & \vdots & \vdots \\
\left(\left[\mu_{m 1}^{-}, \mu_{m 1}^{+}\right],\left[v_{m 1}^{-}, v_{m 1}^{+}\right]\right) & \left(\left[\mu_{m 2}^{-}, \mu_{m 2}^{+}\right],\left[v_{m 2}^{-}, v_{m 2}^{+}\right]\right) & \cdots & \left(\left[\mu_{m n}^{-}, \mu_{m n}^{+}\right],\left[v_{m n}^{-}, v_{m n}^{+}\right]\right)
\end{array}\right)
$$

We give the concepts of IVIF-PIS, IVIF-NIS, and satisfaction degree before the decision-making algorithm is given.

Considering the decision information represents the form of IVIFVs, we use (5) and (6) based on comparison approach to identify the IVIF-PIS and the IVIF-NIS. We use $\mathrm{O}^{+}$to represent IVIF-PIS and $\mathrm{O}^{-}$to represent IVIF-NIS; they are determined as follows:

$$
\begin{aligned}
O^{+} & =\left\{\left\langle C_{j}, \max _{i} s\left(C_{j}\left(x_{i}\right)\right)\right\rangle \mid j=1,2, \ldots, n ; i\right. \\
& =1,2, \ldots, m\}, \\
O^{-} & =\left\{\left\langle C_{j}, \operatorname{mim}_{i} s\left(C_{j}\left(x_{i}\right)\right)\right\rangle \mid j=1,2, \ldots, n ; i\right. \\
& =1,2, \ldots, m\} .
\end{aligned}
$$

Let $\mathrm{D}$ be one of IPIVIFOWAD and PIVIFOWAD, and $\mathrm{D}\left(\mathrm{O}^{+}, \mathrm{O}_{i}\right)$ and $\mathrm{D}\left(\mathrm{O}^{+}, \mathrm{O}_{i}\right)$ denote the distance of $\mathrm{O}^{+}$and alternative $O_{i}$ and the $O^{-}$and alternative $O_{i}$, respectively. Motivated by the well-known TOPSIS, we take both $\mathrm{D}\left(\mathrm{O}^{+}, \mathrm{O}_{i}\right)$ and $\mathrm{D}\left(\mathrm{O}^{-}, \mathrm{O}_{i}\right)$ into consideration simultaneously rather than separately. This leads naturally to the concept of satisfaction degree.

Definition 5. Let $A=\left\{A_{1}, \ldots, A_{m}\right\}$ be a collection of alternatives. The satisfaction degree $\lambda\left(O_{i}\right)$ of a given alternative $x_{i}$ over the criteria $C_{j}(j=1,2, \ldots, n)$ is defined as

$$
\begin{array}{r}
\lambda\left(O_{i}\right)=\frac{(1-\varepsilon)\left[D\left(O^{-}, O_{i}\right)\right]}{\varepsilon\left[D\left(O^{+}, O_{i}\right)\right]+(1-\varepsilon)\left[D\left(O^{-}, O_{i}\right)\right]}, \\
i=1,2, \ldots, m .
\end{array}
$$

In (21), $\varepsilon$ denotes the risk preference of the DM and $\varepsilon \in[0,1]$ : $\varepsilon>0.5$ means that the decision maker is pessimist, while $\varepsilon<0.5$ means the opposite. $\varepsilon=0.5$ : satisfaction degree is of relative closeness using the classic TOPSIS method. The parameter $\varepsilon$ is provided by the DM in advance. It is obvious that $\lambda\left(O_{i}\right) \in[0,1](i=1,2, \ldots, m)$. The higher the satisfaction degree, the better the alternative.

\subsection{Decision Algorithm for MCDM with IVIF}

Step 1. Determine the IVIF-PIS and the IVIF-NIS.

Step 2. Calculate the distance between IVIFVs in $A$ and IVIFVs in $\mathrm{O}^{+}\left(\mathrm{O}^{-}\right)$according to (9).

Step 3. Recalculate the probability according to distance calculated in Step 2.

Step 4. Compute the distance $\mathrm{D}\left(\mathrm{O}^{+}, \mathrm{O}_{i}\right)$ of the positive ideal IVIFS $\mathrm{O}^{+}$and alternative $\mathrm{O}_{i}$ and the distance $\mathrm{D}\left(\mathrm{O}^{-}, \mathrm{O}_{i}\right)$ of the negative ideal IVIFS $\mathrm{O}^{-}$and alternative $O_{i}$, respectively.

Step 5. Calculate the satisfaction degree $\lambda\left(O_{i}\right)$ according to Definition 5. And get the priority of the alternative $O_{i}(i=$ $1, \ldots, m)$ by ranking $\lambda\left(O_{i}\right)(i=1, \ldots, m)$; the bigger the satisfaction degree $\lambda\left(O_{i}\right)$, the better the alternation $O_{i}$.

Step 6. End.

\section{Case Study}

In this section, we will give a practical example about the optimal invest strategy to show the application of the proposed IPIVIFOWAD and PIVIFOWAD.

Technological innovation not only is directly related to the survival and development of an enterprise, but also affects the economic development of a region or even a country. As we all know, the management of an enterprise's technological innovation activities is an important manifestation of its technological innovation capability. In evaluating the technological innovation capability of enterprises, the following evaluation index system should be considered: 
(1) $G_{1}$ : innovation system construction, attitude to innovation failure, and incentives for innovation by the enterprise distribution system;

(2) $G_{2}$ : establishment and implementation of technological innovation strategy, the formation, and maintenance of enterprise innovation culture;

(3) $G_{3}$ : the feasibility of research and development project feasibility report;

(4) $G_{4}$ : the completeness of the monitoring;

(5) $G_{5}$ : evaluation system and innovation awareness of leaders and staff.

$\mathrm{DM}$ assesses the technical innovation management of 5 large enterprises $O_{i}(i=1, \ldots, 5)$ by questionnaires survey and discussion and uses the IVIFVs for evaluation and constructs the IVIF decision matrix as shown in Table 1.

To find the desirable alternative, the experts give the probabilistic weight information as follows: $p=(0.3,0.3,0.2,0.1$, $0.1)$. They assume that the importance degree of each characteristic is $w=(0.2,0.3,0.1,0.3,0.1)$.

\subsection{Decision-Making Using IPIVIFOWAD Operator}

Step 1. Determine the IVIF-PIS $\mathrm{O}^{+}$and the IVIF-NIS $\mathrm{O}^{-}$by (5) and (6) which are shown in Table 2.

We can see from Table 2 that $s_{j}\left(G_{1}\right)(j=1,2,3,4,5)$ all are different, so do $s_{j}\left(G_{2}\right), s_{j}\left(G_{3}\right), s_{j}\left(G_{4}\right), s_{j}\left(G_{5}\right)(j=1,2,3,4,5)$. Therefore, we do not need to compute the accuracy function. And so, IVIF-PIS $\mathrm{O}^{+}$and IVIF-NIS $\mathrm{O}^{-}$are obtained, respectively, and shown as follows:

$$
\begin{gathered}
O^{+}=\left\{\left\langle G_{1},([0.6,0.7],[0.2,0.3])\right\rangle,\right. \\
\left\langle G_{2},([0.6,0.7],[0.1,0.2])\right\rangle, \\
\left\langle G_{3},([0.6,0.7],[0.2,0.3])\right\rangle, \\
\left\langle G_{4},([0.7,0.8],[0.1,0.2])\right\rangle, \\
\left.\left\langle G_{5},([0.6,0.7],[0.2,0.3])\right\rangle\right\}, \\
O^{-}=\left\{\left\langle G_{1},([0.3,0.4],[0.5,0.6])\right\rangle,\right. \\
\left\langle G_{2},([0.2,0.3],[0.6,0.7])\right\rangle, \\
\left\langle G_{3},([0.4,0.5],[0.3,0.4])\right\rangle, \\
\left\langle G_{4},([0.2,0.3],[0.5,0.6])\right\rangle, \\
\left.\left\langle G_{5},([0.3,0.4],[0.4,0.5])\right\rangle\right\} .
\end{gathered}
$$

Step 2. Denote $O^{+}=\left\{\tilde{\gamma}_{1}, \ldots, \tilde{\gamma}_{5}\right\}, O^{-}=\left\{\tilde{\tau}_{1}, \ldots, \tilde{\tau}_{5}\right\}, O_{i}=\left\{\tilde{a}_{i 1}\right.$, $\left.\ldots, \tilde{a}_{i 5}\right\}(i=1,2, \ldots, 5)$. Now we calculate the distance $d\left(\tilde{\gamma}_{j}, \widetilde{a}_{i j}\right)(i, j=1,2, \ldots, 5)$ between IVIFVs $\tilde{\gamma}_{j}, \tilde{a}_{i j}, d\left(\tilde{\tau}_{j}, \tilde{a}_{i j}\right)(i$, $j=1,2, \ldots, 5)$ between the IVIFVs $\widetilde{\tau}_{j}, \widetilde{a}_{i j}$, respectively. The results can be found in Tables 3 and 4 .

Step 3. Calculate IP by using the above probabilities and weights according to Tables 3 and 4 . The results are shown in Tables 5 and 6.
Step 4. Calculate the IPIVIFOWAD $\left(\mathrm{O}_{i}, \mathrm{O}^{+}\right)$and IPIVIFOWAD $\left(O_{i}, O^{-}\right)$according to Step 2 and Step 3. For convenience, we denote $\operatorname{IPIVIFOWAD}\left(\mathrm{O}_{i}, \mathrm{O}^{+}\right)$and IPIVIFOWAD $\left(O_{i}, O^{-}\right)$as $D\left(O_{i}, O^{+}\right)$and $D\left(O_{i}, O^{-}\right)(i=$ $1,2, \ldots, 5)$, respectively. The results are as follows.

$$
\begin{aligned}
& D\left(O_{1}, O^{+}\right)=0.0579, \\
& D\left(O_{2}, O^{+}\right)=0.2979, \\
& D\left(O_{3}, O^{+}\right)=0.1842, \\
& D\left(O_{4}, O^{+}\right)=0.1957, \\
& D\left(O_{5}, O^{+}\right)=0.1167 . \\
& D\left(O_{1}, O^{-}\right)=0.2474, \\
& D\left(O_{2}, O^{-}\right)=0.1105, \\
& D\left(O_{3}, O^{-}\right)=0.2214, \\
& D\left(O_{4}, O^{-}\right)=0.1905, \\
& D\left(O_{5}, O^{-}\right)=0.2816 .
\end{aligned}
$$

Step 5. Calculate the satisfaction degree according to the distance in Step 4. The results can be found in Table 7 under different risk preference $\varepsilon$.

It follows from Table 7 that the order of alternatives is consistent with results by using IPIVIFOWAD when parameter changes. We can obtain the ranking $\mathrm{O}_{1}>\mathrm{O}_{5}>\mathrm{O}_{3}>\mathrm{O}_{4}>$ $\mathrm{O}_{2}$. All of the results show that $\mathrm{O}_{1}$ is the desirable alternative. Such a conclusion can be drawn directly from Figure 1.

5.2. Decision-Making Using PIVIFOWAD. Now we use the PIVIFOWAD to this decision-making problem. According to the distance matrices in Tables 3 and 4, note that the WA has an importance of 40 percent and the probabilistic information has an importance of 60 percent. We can rearrange the probabilistic information according the distance. The results can be found in Tables 8 and 9.

Therefore, we can calculate PIVIFOWAD distances $D\left(O_{i}, O^{+}\right), D\left(O_{i}, O^{-}\right)(i=1, \ldots, 5)$ as follows:

$$
\begin{aligned}
& D\left(O_{1}, O^{+}\right)=0.076, \\
& D\left(O_{2}, O^{+}\right)=0.281, \\
& D\left(O_{3}, O^{+}\right)=0.208, \\
& D\left(O_{4}, O^{+}\right)=0.192, \\
& D\left(O_{5}, O^{+}\right)=0.123 . \\
& D\left(O_{1}, O^{-}\right)=0.228, \\
& D\left(O_{2}, O^{-}\right)=0.14, \\
& D\left(O_{3}, O^{-}\right)=0.179,
\end{aligned}
$$


TABLE 1: IVIF decision matrix.

\begin{tabular}{cccccc}
\hline & $G_{1}$ & $G_{2}$ & $G_{3}$ & $G_{4}$ & $G_{5}$ \\
\hline$O_{1}$ & $([0.6,0.7],[0.2,0.3])$ & $([0.6,0.7],[0.1,0.2])$ & $([0.5,0.6],[0.3,0.4])$ & $([0.4,0.5],[0.2,0.3])$ & $([0.5,0.6],[0.3,0.4])$ \\
$O_{2}$ & $([0.3,0.4],[0.5,0.6])$ & $([0.2,0.3],[0.6,0.7])$ & $([0.4,0.6],[0.2,0.3])$ & $([0.7,0.7],[0.1,0.2])$ & $([0.4,0.6],[0.1,0.2])$ \\
$O_{3}$ & $([0.5,0.6],[0.2,0.4])$ & $([0.5,0.7],[0.2,0.3])$ & $([0.4,0.5],[0.3,0.4])$ & $([0.2,0.3],[0.5,0.6])$ & $([0.3,0.4],[0.4,0.5])$ \\
$O_{4}$ & $([0.3,0.4],[0.4,0.5])$ & $([0.5,0.6],[0.3,0.4])$ & $([0.5,0.6],[0.2,0.3])$ & $([0.5,0.6],[0.2,0.3])$ & $([0.5,0.6],[0.2,0.3])$ \\
$O_{5}$ & $([0.4,0.6],[0.2,0.4])$ & $([0.5,0.6],[0.2,0.3])$ & $([0.6,0.7],[0.2,0.3])$ & $([0.3,0.4],[0.5,0.6])$ & $([0.6,0.7],[0.2,0.3])$ \\
\hline
\end{tabular}

TABLE 2: The results by using score function.

\begin{tabular}{lccccc}
\hline & $G_{1}$ & $G_{2}$ & $G_{3}$ & $G_{4}$ & \\
\hline$s_{1}$ & 0.4 & 0.5 & 0.2 & 0.2 & 0.2 \\
$s_{2}$ & -0.2 & -0.4 & 0.25 & 0.6 & 0.35 \\
$s_{3}$ & 0.25 & 0.35 & 0.1 & -0.3 & -0.1 \\
$s_{4}$ & -0.1 & 0.2 & 0.3 & 0.3 & 0.3 \\
$s_{5}$ & 0.2 & 0.3 & 0.4 & -0.2 & 0.4 \\
\hline
\end{tabular}

TABLE 3: The distance between $\widetilde{a}_{i j}$ and $\widetilde{\gamma}_{j}$.

\begin{tabular}{lccccc}
\hline & $\tilde{\gamma}_{1}$ & $\tilde{\gamma}_{2}$ & $\tilde{\gamma}_{3}$ & $\tilde{\gamma}_{4}$ & 0.3 \\
\hline $\mathrm{O}_{1}$ & 0 & 0 & 0.1 & 0 & 0.1 \\
$\mathrm{O}_{2}$ & 0.3 & 0.5 & 0.15 & 0.5 & 0.25 \\
$\mathrm{O}_{3}$ & 0.1 & 0.1 & 0.2 & 0.2 & 0.3 \\
$\mathrm{O}_{4}$ & 0.3 & 0.2 & 0.1 & 0.1 & 0.4 \\
$\mathrm{O}_{5}$ & 0.15 & 0.1 & 0 & 0.1 \\
\hline
\end{tabular}

TABLE 4: The distance between $\tilde{a}_{i j}$ and $\tilde{\tau}_{j}$.

\begin{tabular}{lccccc}
\hline & $\tilde{\tau}_{1}$ & $\widetilde{\tau}_{2}$ & $\tilde{\tau}_{3}$ & $\tilde{\tau}_{4}$ & 0.3 \\
\hline $\mathrm{O}_{1}$ & 0.3 & 0.5 & 0.1 & 0.5 & 0.2 \\
$\mathrm{O}_{2}$ & 0 & 0 & 0.1 & 0 & 0.3 \\
$\mathrm{O}_{3}$ & 0.25 & 0.4 & 0 & 0.3 & 0 \\
$\mathrm{O}_{4}$ & 0.1 & 0.3 & 0.1 & 0.3 & 0.2 \\
$\mathrm{O}_{5}$ & 0.25 & 0.4 & 0.2 & 0.3 \\
\hline
\end{tabular}

TABle 5: The IP according to Table 3.

\begin{tabular}{lccccc}
\hline & $G_{1}$ & $G_{2}$ & $G_{3}$ & $G_{4}$ & $G_{5}$ \\
\hline$I P_{1}$ & 0.1053 & 0.1579 & 0.1053 & 0.4737 & 0.1579 \\
$I P_{2}$ & 0.2609 & 0.3913 & 0.0435 & 0.2609 & 0.0435 \\
$I P_{3}$ & 0.1053 & 0.1579 & 0.1053 & 0.2607 & 0.1579 \\
$I P_{4}$ & 0.2607 & 0.3913 & 0.0435 & 0.2857 & 0.0435 \\
$I P_{5}$ & 0.0952 & 0.4286 & 0.1429 & 0.0476 \\
\hline
\end{tabular}

TABle 6: The IP according to Table 4.

\begin{tabular}{lccccc}
\hline & $G_{1}$ & $G_{2}$ & $G_{3}$ & $G_{4}$ & 0.3158 \\
\hline$I P_{1}$ & 0.3158 & 0.1579 & 0.0526 & 0.4737 & 0.1579 \\
$I P_{2}$ & 0.1053 & 0.1579 & 0.1053 & 0.1429 & 0.1579 \\
$I P_{3}$ & 0.2857 & 0.4286 & 0.0952 & 0.4286 & 0.0476 \\
$I P_{4}$ & 0.2857 & 0.1429 & 0.0476 & 0.3158 & 0.0952 \\
$I P_{5}$ & 0.3158 & 0.1579 & 0.1579 & 0.0526 \\
\hline
\end{tabular}


TABLE 7: Satisfaction degree obtained by IPIVIFOWAD under different risk preference parameter $\varepsilon$.

\begin{tabular}{lllllll}
\hline & $\lambda\left(O_{1}\right)$ & $\lambda\left(O_{2}\right)$ & $\lambda\left(O_{3}\right)$ & $\lambda\left(O_{4}\right)$ & $\lambda\left(O_{5}\right)$ & Ranking \\
\hline$\varepsilon=0.1$ & 0.9747 & 0.7696 & 0.9154 & 0.8976 & 0.9560 & $O_{1}>O_{5}>O_{3}>O_{4}>O_{2}$ \\
$\varepsilon=0.3$ & 0.9088 & 0.4641 & 0.7372 & 0.6943 & 0.8492 & $O_{1}>O_{5}>O_{3}>O_{4}>O_{2}$ \\
$\varepsilon=0.5$ & 0.8103 & 0.2707 & 0.5459 & 0.4933 & 0.7070 & $O_{1}>O_{5}>O_{3}>O_{4}>O_{2}$ \\
$\varepsilon=0.7$ & 0.6468 & 0.1372 & 0.3400 & 0.2944 & 0.5084 & $O_{1}>O_{5}>O_{3}>O_{4}>O_{2}$ \\
$\varepsilon=0.9$ & 0.3219 & 0.0396 & 0.1178 & 0.0976 & 0.2115 & $O_{1}>O_{5}>O_{3}>O_{4}>O_{2}$ \\
\hline
\end{tabular}

TABLE 8: The probabilities according to Table 3.

\begin{tabular}{lccccc}
\hline & $G_{1}$ & $G_{2}$ & $G_{3}$ & $G_{4}$ & 0.3 \\
\hline$\hat{p}_{1}$ & 0.14 & 0.18 & 0.16 & 0.24 & 0.22 \\
$\widehat{p}_{2}$ & 0.26 & 0.3 & 0.1 & 0.3 & 0.1 \\
$\widehat{p}_{3}$ & 0.14 & 0.18 & 0.16 & 0.24 & 0.22 \\
$\widehat{p}_{4}$ & 0.26 & 0.3 & 0.1 & 0.1 \\
$\hat{p}_{5}$ & 0.14 & 0.3 & 0.22 & 0.24 \\
\hline
\end{tabular}

TABLE 9: The probabilities according to Table 4.

\begin{tabular}{lccccc}
\hline & $G_{1}$ & $G_{2}$ & $G_{3}$ & $G_{4}$ & 0.24 \\
\hline$\widehat{p}_{1}$ & 0.26 & 0.18 & 0.1 & 0.3 & 0.22 \\
$\widehat{p}_{2}$ & 0.14 & 0.18 & 0.16 & 0.18 & 0.22 \\
$\widehat{p}_{3}$ & 0.26 & 0.3 & 0.16 & 0.3 & 0.1 \\
$\widehat{p}_{4}$ & 0.26 & 0.18 & 0.1 & 0.16 \\
$\widehat{p}_{5}$ & 0.26 & 0.18 & 0.22 & 0.24 \\
\hline
\end{tabular}

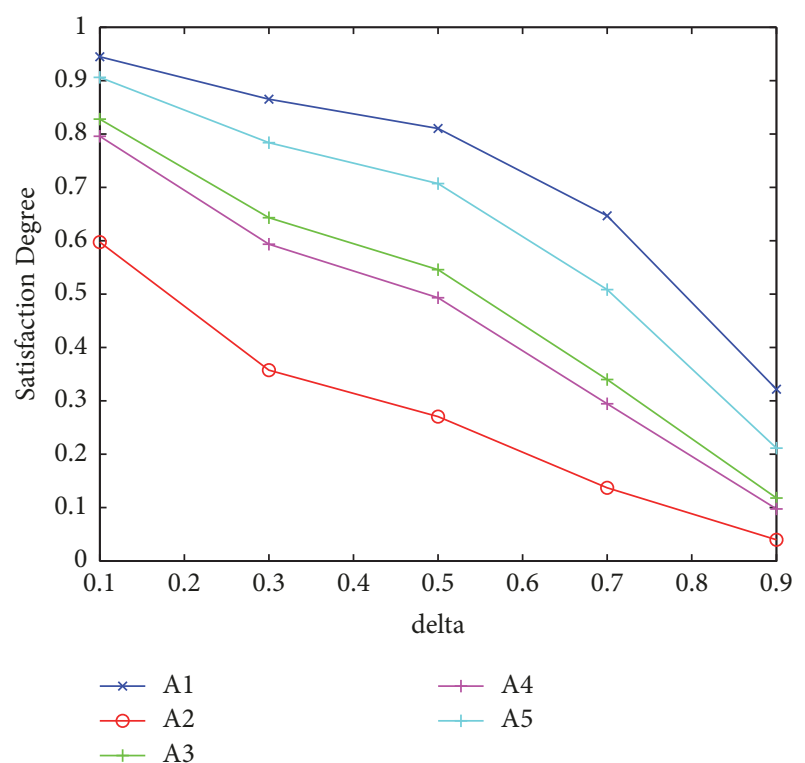

FIGURE 1: Satisfaction degree obtained by IPIVIFOWAD under different $\varepsilon$.

$$
\begin{aligned}
& D\left(\mathrm{O}_{4}, \mathrm{O}^{-}\right)=0.198, \\
& D\left(\mathrm{O}_{5}, \mathrm{O}^{-}\right)=0.271 .
\end{aligned}
$$

Therefore, we can obtain the satisfaction degree under difference risk preference parameters $\varepsilon$; please refer to Table 10.

It follows from Table 10 that the ranking is consistent with the results by using the PIVIFOWAD operators when parameter changes. We can obtain the order of alternatives: $\mathrm{O}_{1}>\mathrm{O}_{3}>\mathrm{O}_{5}>\mathrm{O}_{4}>\mathrm{O}_{2}$. All of the results show that $\mathrm{O}_{1}$ is the desirable one. Such a conclusion can be also drawn directly from Figure 2.

If we change the weight important degree $\xi$, we can obtain other satisfaction degrees listed in Table 11. From Table 11, we can see that the desirable alternative is consistent with the ranking obtained by PIVIFOWAD when parameter $\xi$ changes although the ranking of alternatives is not the same. All of the results show that $O_{1}$ is the desirable one. Such a conclusion can be drawn directly from Figure 3 .

5.3. Effectiveness Test of the Proposed Method. For MCDM problems, Wang and Triantaphyllou [45] established assessing criteria (please refer to [45]) to assess the effectiveness of MCDM methods. In what follows, we will use the above MCDM criteria to test our proposed methods in Section 4. As far as the proposed method based on IPIVIFOWAD is concerned, we choose the satisfactory degree $\varepsilon=0.5$ to analyze the above criteria.

Validity Test for Criterion 1. In Section 5.2, we obtained that $\mathrm{O}_{1}$ is the desirable one and the order of alternatives is 
TABLE 10: Modified IVIF decision matrix.

\begin{tabular}{cccccc}
\hline & $G_{1}$ & $G_{2}$ & $G_{3}$ & $G_{4}$ & $G_{5}$ \\
\hline$O_{1}$ & $([0.6,0.7],[0.2,0.3])$ & $([0.6,0.7],[0.1,0.2])$ & $([0.5,0.6],[0.3,0.4])$ & $([0.4,0.5],[0.2,0.3])$ & $([0.5,0.6],[0.3,0.4])$ \\
$O_{2}$ & $([0.3,0.4],[0.5,0.6])$ & $([0.2,0.3],[0.6,0.7])$ & $([0.4,0.6],[0.2,0.3])$ & $([0.7,0.7],[0.1,0.2])$ & $([0.4,0.6],[0.1,0.2])$ \\
$O_{3}$ & $([0.2,0.4],[0.5,0.6])$ & $([0.2,0.3],[0.5,0.7])$ & $([0.3,0.4],[0.4,0.5])$ & $([0.5,0.6],[0.2,0.3])$ & $([0.4,0.5],[0.3,0.4])$ \\
$O_{4}$ & $([0.4,0.5],[0.3,0.4])$ & $([0.3,0.4],[0.5,0.6])$ & $([0.2,0.3],[0.5,0.6])$ & $([0.2,0.3],[0.5,0.6])$ & $([0.2,0.3],[0.5,0.6])$ \\
$O_{5}$ & $([0.4,0.6],[0.2,0.4])$ & $([0.5,0.6],[0.2,0.3])$ & $([0.6,0.7],[0.2,0.3])$ & $([0.3,0.4],[0.5,0.6])$ & $([0.6,0.7],[0.2,0.3])$ \\
\hline
\end{tabular}

TABLE 11: Satisfaction degree obtained by PIVIFOWAD under different $\xi$.

\begin{tabular}{lllllll}
\hline & $\lambda\left(O_{1}\right)$ & $\lambda\left(O_{2}\right)$ & $\lambda\left(O_{3}\right)$ & $\lambda\left(O_{4}\right)$ & $\lambda\left(O_{5}\right)$ & Ranking \\
\hline$\xi=0.1$ & 0.7762 & 0.2740 & 0.5053 & 0.4923 & 0.7008 & $O_{1}>O_{5}>O_{3}>O_{4}>O_{2}$ \\
$\xi=0.3$ & 0.7584 & 0.3136 & 0.4766 & 0.5027 & 0.6921 & $O_{1}>O_{5}>O_{4}>O_{3}>O_{2}$ \\
$\xi=0.5$ & 0.7419 & 0.3509 & 0.4487 & 0.5128 & 0.6835 & $O_{1}>O_{5}>O_{4}>O_{2}>O_{2}$ \\
$\xi=0.7$ & 0.7267 & 0.3859 & 0.4217 & 0.5231 & 0.6751 & $O_{1}>O_{5}>O_{4}>O_{3}>O_{2}$ \\
$\xi=0.9$ & 0.7126 & 0.4190 & 0.3955 & 0.5333 & 0.6667 & $O_{1}>O_{5}>O_{4}>O_{2}>O_{3}$ \\
\hline
\end{tabular}

TABLE 12: Modified IVIF decision matrix.

\begin{tabular}{cccccc}
\hline & $G_{1}$ & $G_{2}$ & $G_{3}$ & $G_{4}$ & $G_{5}$ \\
\hline$O_{1}$ & $([0.6,0.7],[0.2,0.3])$ & $([0.6,0.7],[0.1,0.2])$ & $([0.5,0.6],[0.3,0.4])$ & $([0.4,0.5],[0.2,0.3])$ & $([0.5,0.6],[0.3,0.4])$ \\
$O_{2}$ & $([0.3,0.4],[0.5,0.6])$ & $([0.2,0.3],[0.6,0.7])$ & $([0.4,0.6],[0.2,0.3])$ & $([0.7,0.7],[0.1,0.2])$ & $([0.4,0.6],[0.1,0.2])$ \\
$O_{3}$ & $([0.2,0.4],[0.5,0.6])$ & $([0.2,0.3],[0.5,0.7])$ & $([0.3,0.4],[0.4,0.5])$ & $([0.5,0.6],[0.2,0.3])$ & $([0.4,0.5],[0.3,0.4])$ \\
$O_{4}$ & $([0.4,0.5],[0.3,0.4])$ & $([0.3,0.4],[0.5,0.6])$ & $([0.2,0.3],[0.5,0.6])$ & $([0.2,0.3],[0.5,0.6])$ & $([0.2,0.3],[0.5,0.6])$ \\
$O_{5}$ & $([0.4,0.6],[0.2,0.4])$ & $([0.5,0.6],[0.2,0.3])$ & $([0.6,0.7],[0.2,0.3])$ & $([0.3,0.4],[0.5,0.6])$ & $([0.6,0.7],[0.2,0.3])$ \\
\hline
\end{tabular}

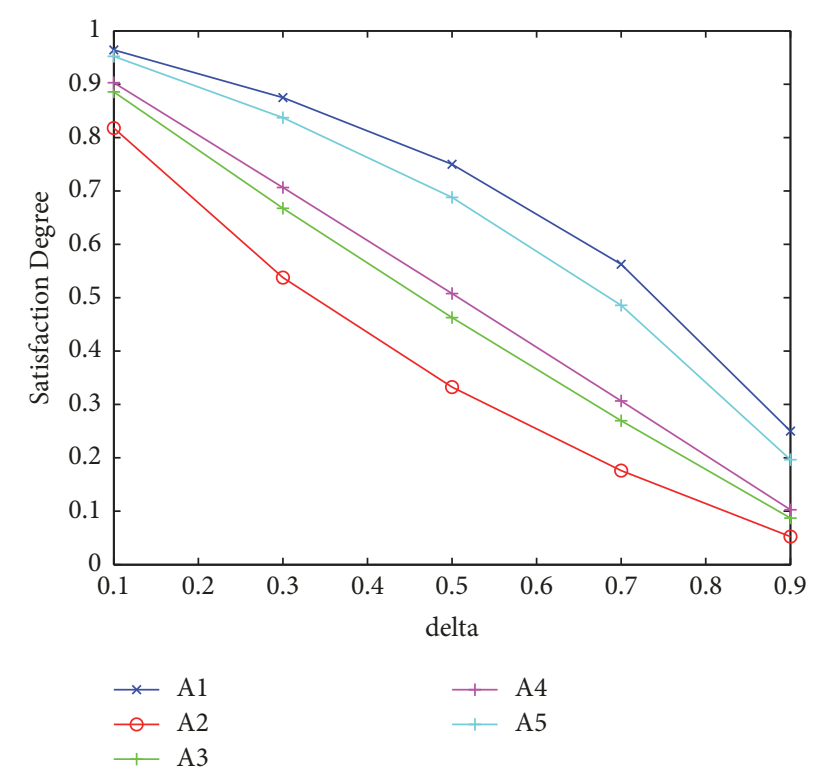

FIGURE 2: Satisfaction degree obtained by PIVIFOWAD under different $\varepsilon$ and $\xi=0.4$.

$\mathrm{O}_{1}>\mathrm{O}_{5}>\mathrm{O}_{3}>\mathrm{O}_{4}>\mathrm{O}_{2}$. In order to test the effectiveness of the developed IPIVIFOWAD method under criterion 1, we construct the modified IVIF decision matrix (Table 12) by interchanging the membership and nonmembership of alternatives $\mathrm{O}_{3}$ and $\mathrm{O}_{4}$ in Table 1 .

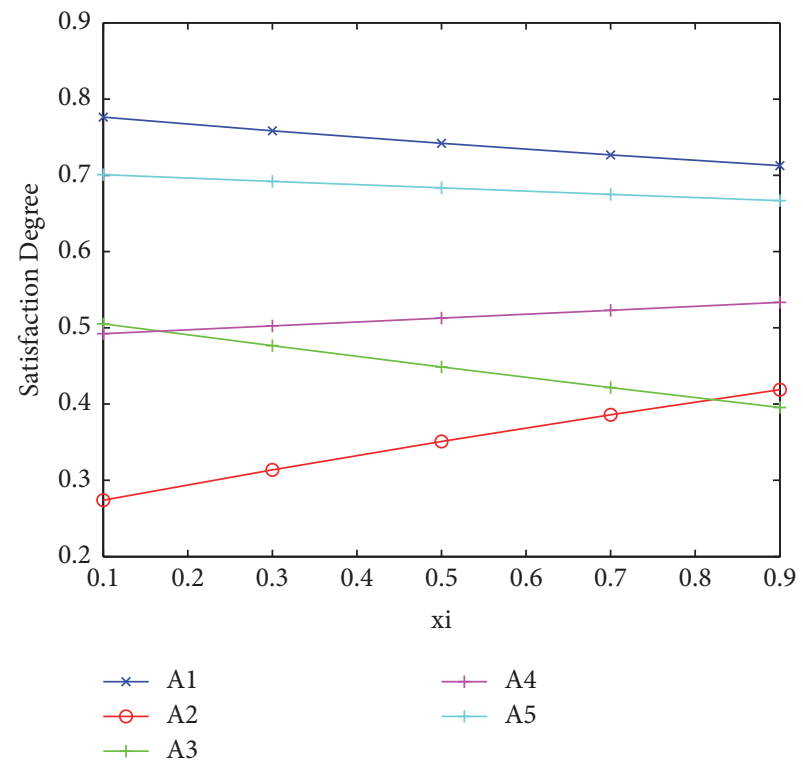

FIGURE 3: Satisfaction degree obtained by PIVIFOWAD under different $\xi$ and $\varepsilon=0.5$.

Repeating the same steps 1-2 in Section 5.1, we can obtain the modified IVIF-PIS $\mathrm{O}^{+}$and the IVIF-NIS $\mathrm{O}^{-}$which are listed as follows: 


$$
\begin{gathered}
O^{+}=\left\{\left\langle G_{1},([0.7,0.8],[0.2,0.3])\right\rangle,\right. \\
\left\langle G_{2},([0.7,0.8],[0.2,0.3])\right\rangle, \\
\left\langle G_{3},([0.8,0.9],[0.3,0.4])\right\rangle, \\
\left\langle G_{4},([0.7,0.8],[0.3,0.5])\right\rangle, \\
\left.\left\langle G_{5},([0.7,0.8],[0.4,0.5])\right\rangle\right\}, \\
O^{-}=\left\{\left\langle G_{1},([0.2,0.4],[0.7,0.8])\right\rangle,\right. \\
\left\langle G_{2},([0.3,0.4],[0.6,0.7])\right\rangle, \\
\left\langle G_{3},([0.3,0.4],[0.6,0.8])\right\rangle, \\
\left\langle G_{4},([0.3,0.5],[0.5,0.6])\right\rangle, \\
\left.\left\langle G_{5},([0.3,0.4],[0.5,0.7])\right\rangle\right\} .
\end{gathered}
$$

Using Step 3-Step 5 of IPIVIFOWAD method, the IPIVIFOWAD distances $D\left(O_{i}, O^{+}\right)$between alternatives $O_{i}$ and $\mathrm{O}^{+}$and the IPIVIFOWAD distances $D\left(O_{i}, \mathrm{O}^{-}\right)$between alternatives $O_{i}$ and $O^{-}$are calculated, respectively, where $i=$ $1,2, \ldots, 5$.

$$
\begin{aligned}
& D\left(O_{1}, O^{+}\right)=0.0579, \\
& D\left(O_{2}, O^{+}\right)=0.2978, \\
& D\left(O_{3}, O^{+}\right)=0.3452, \\
& D\left(O_{4}, O^{+}\right)=0.3789, \\
& D\left(O_{5}, O^{+}\right)=0.1167 . \\
& D\left(O_{1}, O^{-}\right)=0.3786, \\
& D\left(O_{2}, O^{-}\right)=0.3526, \\
& D\left(O_{3}, O^{-}\right)=0.0974, \\
& D\left(O_{4}, O^{-}\right)=0.1, \\
& D\left(O_{5}, O^{-}\right)=0.3243 .
\end{aligned}
$$

According to the satisfaction degree formula when $\varepsilon=$ 0.5 , we have

$$
\begin{aligned}
& \lambda\left(O_{1}\right)=0.8674, \\
& \lambda\left(O_{2}\right)=0.5421, \\
& \lambda\left(O_{3}\right)=0.2200, \\
& \lambda\left(O_{4}\right)=0.2088, \\
& \lambda\left(O_{5}\right)=0.7355 .
\end{aligned}
$$

We can see from the above satisfaction degrees that the rank is $O_{1}>O_{5}>O_{2}>O_{3}>O_{4}$; that is, $O_{1}$ is the best one. Therefore, the best alternative coincides with the best alternative obtained in Section 5.1 by the same method, and the relative orders of the rest of the unchanged alternatives keep constant. That is, Criterion 1 is suitable for the proposed method.

Validity Test for Criterion 2 and Criterion 3. According to the requirements of criterion 2 and test criterion 3 introduced in [45], the original problem should be decomposed into two smaller MCDM problems, such as $\left\{\mathrm{O}_{1}, O_{2}, O_{3}, O_{4}\right\}$ and $\left\{O_{1}, O_{3}, O_{4}, O_{5}\right\}$. For the subproblem $\left\{O_{1}, O_{2}, O_{3}, O_{4}\right\}$, we can obtain the satisfaction degree by repeating Step 1 to Step 6 as follows:

$$
\begin{aligned}
& \lambda\left(O_{1}\right)=0.7988, \\
& \lambda\left(O_{2}\right)=0.2859, \\
& \lambda\left(O_{3}\right)=0.56048, \\
& \lambda\left(O_{4}\right)=0.48488 .
\end{aligned}
$$

Therefore, the ranking of the subproblem is $\mathrm{O}_{1}>\mathrm{O}_{3}>\mathrm{O}_{4}>$ $\mathrm{O}_{2}$. For the subproblem $\left\{\mathrm{O}_{1}, \mathrm{O}_{3}, \mathrm{O}_{4}, \mathrm{O}_{5}\right\}$, we can obtain the satisfaction degree by repeating Step 1 to Step 6 as follows:

$$
\begin{aligned}
& \lambda\left(O_{1}\right)=0.8577, \\
& \lambda\left(O_{3}\right)=0.38, \\
& \lambda\left(O_{4}\right)=0.2740, \\
& \lambda\left(O_{5}\right)=0.6066 .
\end{aligned}
$$

The ranking of the subproblem $\left\{O_{1}, O_{3}, O_{4}, O_{5}\right\}$ is $O_{1}>O_{5}>$ $\mathrm{O}_{3}>\mathrm{O}_{4}$.

We obtain the final ranking $\mathrm{O}_{1}>\mathrm{O}_{5}>\mathrm{O}_{3}>\mathrm{O}_{4}>$ $\mathrm{O}_{2}$ by combining the order of alternatives of subproblems $\left\{O_{1}, O_{2}, O_{3}, O_{4}\right\}$ and $\left\{O_{1}, O_{3}, O_{4}, O_{5}\right\}$, and the final order is the same as the order of original decision problem and it also exhibits transitive property. Criterion 2 and criterion 3 proposed in [45] are also suitable for the proposed method.

5.4. Comparison with Existing Work. For the comparison with Hadi-Vencheh and Mirjaberi's method [46], in the classical TOPSIS method, we often need to compute the relative closeness of the alternative $O_{i}$ with respect to the PIS $\mathrm{O}^{+}$ as below:

$$
R C\left(O_{i}\right)=\frac{D\left(O_{i}, O^{-}\right)}{D\left(O_{i}, O^{-}\right)+D\left(O_{i}, O^{+}\right)}
$$

$D($.$) is a distance measure. The ranking of all alternatives can$ be determined according to the closeness index $R C\left(O_{i}\right)$. If $\varepsilon=$ 0.5 in our proposed equation (21), then (21) will be (30).

However, Hadi-Vencheh and Mirjaberi[46] suggested that one may use the following formula instead of the relative closeness index:

$$
\zeta\left(O_{i}\right)=\frac{D\left(O_{i}, O^{-}\right)}{D_{\max }\left(O_{i}, O^{-}\right)}-\frac{D\left(O_{i}, O^{+}\right)}{D_{\min }\left(O_{i}, O^{+}\right)}
$$

$D_{\max }\left(O_{i}, O^{-}\right)=\max _{1 \leq i \leq m}\left\{D\left(O_{i}, O^{-}\right)\right\}$and $D_{\min }\left(O_{i}, O^{+}\right)=$ $\min _{1 \leq i \leq m}\left\{D\left(O_{i}, O^{+}\right)\right\}$. Equation (31) is called the revised 
closeness used to measure the extent to which the alternative $\mathrm{O}_{i}$ is close to the PIS $\mathrm{O}^{+}$and is far away from the NIS $\mathrm{O}^{+}$, simultaneously. By (31),

$$
\begin{aligned}
& \zeta\left(O_{1}\right)=-0.1213 \\
& \zeta\left(O_{2}\right)=-4.751 \\
& \zeta\left(O_{3}\right)=-2.3954 \\
& \zeta\left(O_{4}\right)=-2.7029 \\
& \zeta\left(O_{5}\right)=-1.0151
\end{aligned}
$$

Therefore, the ranking of $\left\{\mathrm{O}_{1}, \mathrm{O}_{2}, \mathrm{O}_{3}, \mathrm{O}_{4}, \mathrm{O}_{5}\right\}$ is arranged $\mathrm{O}_{1}>\mathrm{O}_{5}>\mathrm{O}_{3}>\mathrm{O}_{4}>\mathrm{O}_{2}$ which coincides with our proposed method.

\section{Conclusion}

IVIFSs, which are a generalization of the IFSs, have been used widely in decision problems. IVIFS permits the membership degrees and nonmembership degrees to a given set to have an interval value in $[0,1]$ and can be considered as a powerful tool to express complex information in the human decision-making process. In this paper, we introduced some new distance measures, namely, PIVIFOWAD operator and IPIVIFOWAD operator, while, with respect to probabilistic decision-making problems with IVIF information, some new probabilistic decision-making analysis methods are developed. The new distance operators such as IVIFOWAD operator, PIVIFOWAD operator, and IPIVIFOWAD operator have been developed in this paper, while the concept of satisfaction degree of alternatives has been introduced based on some distance measures and applied to MCDM problem with IVIF information.

\section{Conflicts of Interest}

The authors declare that there are no conflicts of interest regarding the publication of this paper.

\section{Acknowledgments}

This work is supported by National Natural Science Foundation of China (Grant no. 61673320); The Scientific Research Project of Department of Education of Sichuan Province (15TD0027, 18ZA0273); Natural Science Foundation of Guangdong Province (2016A030310003).

\section{References}

[1] K. Atanassov and G. Gargov, "Interval valued intuitionistic fuzzy sets," Fuzzy Sets and Systems, vol. 31, no. 3, pp. 343-349, 1989.

[2] K. T. Atanassov, "Operators over interval valued intuitionistic fuzzy sets," Fuzzy Sets and Systems, vol. 64, no. 2, pp. 159-174, 1994.

[3] K. T. Atanassov, "Intuitionistic fuzzy sets," Fuzzy Sets and Systems, vol. 20, no. 1, pp. 87-96, 1986.
[4] S.-M. Chen and Z.-C. Huang, "Multiattribute decision making based on interval-valued intuitionistic fuzzy values and particle swarm optimization techniques," Information Sciences, vol. 397398, pp. 206-218, 2017.

[5] D. Liu, X. Chen, and D. Peng, "Interval-valued intuitionistic fuzzy ordered weighted cosine similarity measure and its application in investment decision-making," Complexity, 2017.

[6] H. Ren and G. Wang, "An interval-valued intuitionistic fuzzy MADM method based on a new similarity measure," Information, vol. 6, no. 4, pp. 880-894, 2015.

[7] H.-Y. Zhang, S.-Y. Yang, and Z.-W. Yue, "On inclusion measures of intuitionistic and interval-valued intuitionistic fuzzy values and their applications to group decision making," International Journal of Machine Learning and Cybernetics, vol. 7, no. 5, pp. 833-843, 2016.

[8] H. Nguyen, "A new interval-valued knowledge measure for interval-valued intuitionistic fuzzy sets and application in decision making," Expert Systems with Applications, vol. 56, pp. 143155, 2016.

[9] X. Y. Zhao, S. Tang, S. Yang, and K. Huang, "Extended VIKOR method based on cross-entropy for interval-valued intuitionistic fuzzy multiple criteria group decision making," Journal of Intelligent and Fuzzy Systems, vol. 25, pp. 1053-1066, 2013.

[10] Z. S. Xu, "A method based on distance measure for intervalvalued intuitionistic fuzzy group decision making," Information Sciences, vol. 180, no. 1, pp. 181-190, 2010.

[11] P. Liu, "Multiple attribute group decision making method based on interval-valued intuitionistic fuzzy power Heronian aggregation operators," Computers \& Industrial Engineering, vol. 108, pp. 199-212, 2017.

[12] P. D. Liu, "Some Hamacher aggregation operators based on the interval-valued intuitionistic fuzzy numbers and their application to group decision making," IEEE Transactions on Fuzzy Systems, vol. 22, no. 1, pp. 83-97, 2014.

[13] P. Liu and X. Liu, "Multiattribute group decision making methods based on linguistic intuitionistic fuzzy power Bonferroni mean operators," Complexity, 2017.

[14] P. Liu and F. Teng, "Multiple criteria decision making method based on normal interval-valued intuitionistic fuzzy generalized aggregation operator," Complexity, vol. 21, no. 5, pp. 277290, 2016.

[15] P. Liu and S.-M. Chen, "Multiattribute group decision making based on intuitionistic 2-tuple linguistic information," Information Sciences, vol. 430/431, pp. 599-619, 2018.

[16] P. Liu, J. Liu, and J. M. Merigó, "Partitioned Heronian means based on linguistic intuitionistic fuzzy numbers for dealing with multi-attribute group decision making," Applied Soft Computing, vol. 62, pp. 395-422, 2018.

[17] P. Liu and S.-M. Chen, "Group Decision Making Based on Heronian Aggregation Operators of Intuitionistic Fuzzy Numbers," IEEE Transactions on Cybernetics, 2016.

[18] P. Liu, S.-M. Chen, and J. Liu, "Multiple attribute group decision making based on intuitionistic fuzzy interaction partitioned Bonferroni mean operators," Information Sciences, vol. 411, pp. 98-121, 2017.

[19] W. Wang and X. Liu, "The multi-attribute decision making method based on interval-valued intuitionistic fuzzy Einstein hybrid weighted geometric operator," Computers \& Mathematics with Applications, vol. 66, no. 10, pp. 1845-1856, 2013.

[20] H. Liao and Z. Xu, "Intuitionistic fuzzy hybrid weighted aggregation operators," International Journal of Intelligent Systems, vol. 29, no. 11, pp. 971-993, 2014. 
[21] H. Wu and X. Su, "Interval-valued intuitionistic fuzzy prioritized hybrid weighted aggregation operator and its application in decision making," Journal of Intelligent and Fuzzy Systems, vol. 29, no. 4, pp. 1697-1709, 2015.

[22] S. Xiao, "Induced interval-valued intuitionistic fuzzy Hamacher ordered weighted geometric operator and their application to multiple attribute decision making," Journal of Intelligent and Fuzzy Systems, vol. 27, no. 1, pp. 527-534, 2014.

[23] S.-M. Chen and C.-H. Chiou, "Multiattribute Decision Making Based on Interval-Valued Intuitionistic Fuzzy Sets, PSO Techniques, and Evidential Reasoning Methodology," IEEE Transactions on Fuzzy Systems, vol. 23, no. 6, pp. 1905-1916, 2015.

[24] S.-M. Chen, S.-H. Cheng, and W.-H. Tsai, "Multiple attribute group decision making based on interval-valued intuitionistic fuzzy aggregation operators and transformation techniques of interval-valued intuitionistic fuzzy values," Information Sciences, vol. 367-368, pp. 418-442, 2016.

[25] J. Wu, Q. Cao, and H. Li, "An approach for MADM problems with interval-valued intuitionistic fuzzy sets based on nonlinear functions," Technological and Economic Development of Economy, vol. 22, no. 3, pp. 336-356, 2016.

[26] J. H. Park, H. J. Cho, and Y. C. Kwun, "Extension of the VIKOR method for group decision making with interval-valued intuitionistic fuzzy information," Fuzzy Optimization and Decision Making, vol. 10, pp. 233-253, 2011.

[27] S. M. Chen, L. W. Lee, H. C. Liu, and S. W. Yang, "Multiattribute decision making based on interval-valued intuitionistic fuzzy values," Expert Systems with Applications, vol. 39, no. 12, pp. 10343-10351, 2012.

[28] Z. Chen, X. Yang, and Y. Zhu, "Approach to multiple attribute decision making with interval-valued intuitionistic fuzzy information and its application," Journal of Intelligent and Fuzzy Systems, vol. 29, no. 2, pp. 489-497, 2015.

[29] P. Liu and F. Teng, "An extended TODIM method for multiple attribute group decision-making based on 2-dimension uncertain linguistic variable," Complexity, vol. 21, no. 5, pp. 20-30, 2016.

[30] Z. Tao, X. Liu, H. Chen, and L. Zhou, "Ranking Interval-Valued Fuzzy Numbers with Intuitionistic Fuzzy Possibility Degree and Its Application to Fuzzy Multi-Attribute Decision Making," International Jornal of Fuzzy Systems, vol. 19, pp. 646-658, 2016.

[31] Z. Wang, K. W. Li, and W. Wang, "An approach to multiattribute decision making with interval-valued intuitionistic fuzzy assessments and incomplete weights," Information Sciences, vol. 179, no. 17, pp. 3026-3040, 2009.

[32] L. Zhou, Z. Tao, H. Chen, and J. Liu, "Continuous interval-valued intuitionistic fuzzy aggregation operators and their applications to group decision making," Applied Mathematical Modelling, vol. 38, pp. 2190-2205, 2014.

[33] Z. Xu and J. Chen, "Ordered weighted distance measure," Journal of Systems Science and Systems Engineering, vol. 17, no. 4, pp. 432-445, 2008.

[34] J. M. Merigó, "A unified model between the weighted average and the induced OWA operator," Expert Systems with Applications, vol. 38, no. 9, pp. 11560-11572, 2011.

[35] J. M. Merigó and A. M. Gil-Lafuente, "New decision-making techniques and their application in the selection of financial products," Information Sciences, vol. 180, no. 11, pp. 2085-2094, 2010 .
[36] J. M. Merigó and G. Wei, "Probabilistic aggregation operators and their application in uncertain multi-person decisionmaking," Technological and Economic Development of Economy, vol. 17, no. 2, pp. 335-351, 2011.

[37] J. M. Merigó and M. Casanovas, "Decision-making with distance measures and induced aggregation operators," Computers \& Industrial Engineering, vol. 60, no. 1, pp. 66-76, 2011.

[38] J. M. Merig, "Fuzzy multi-person decision making with fuzzy probabilistic aggregation operators," International Journal of Fuzzy Systems, vol. 13, no. 3, pp. 163-174, 2011.

[39] J. M. Merigó, "Fuzzy decision making with immediate probabilities," Computers \& Industrial Engineering, vol. 58, no. 4, pp. 651-657, 2010.

[40] G. W. Wei and J. M. Merigó, "Methods for strategic decisionmaking problems with immediate probabilities in intuitionistic fuzzy setting," Scientia Iranica, vol. 19, no. 6, pp. 1936-1946, 2012.

[41] C. Q. Tan, "A multi-criteria interval-valued intuitionistic fuzzy group decision making with Choquet integral-based TOPSIS," Expert Systems with Applications, vol. 38, no. 4, pp. 3023-3033, 2011.

[42] R. R. Yager, "On ordered weighted averaging aggregation operators in multi-criteria decision making," IEEE Trans. Syst. Man Cybern, vol. 18, pp. 183-190, 1988.

[43] R. R. Yager, K. J. Engemann, and D. P. Filev, "On the concept of immediate probabilities," International Journal of Intelligent Systems, vol. 10, no. 4, pp. 373-397, 1995.

[44] Y. Liu, Y. Qin, and Y. Han, "Multiple criteria decision making with probabilities in interval-valued pythagorean fuzzy setting," International Journal of Fuzzy Systems, vol. 20, no. 2, pp. 558571, 2018.

[45] X. Wang and E. Triantaphyllou, "Ranking irregularities when evaluating alternatives by using some ELECTRE methods," Omega, vol. 36, no. 1, pp. 45-63, 2008.

[46] A. Hadi-Vencheh and M. Mirjaberi, "Fuzzy inferior ratio method for multiple attribute decision making problems," Information Sciences, vol. 277, pp. 263-272, 2014. 


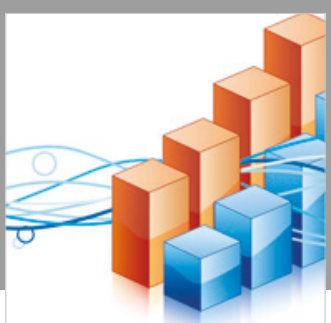

Advances in

Operations Research

\section{-n-m}
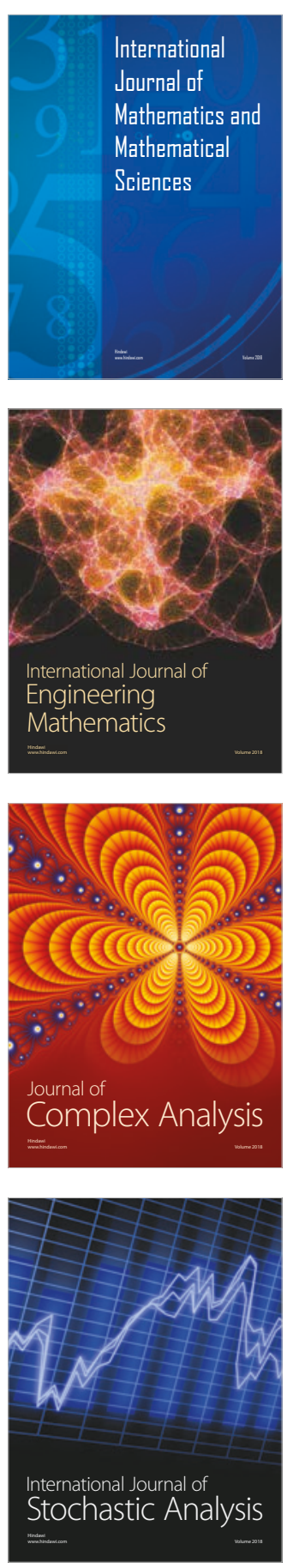
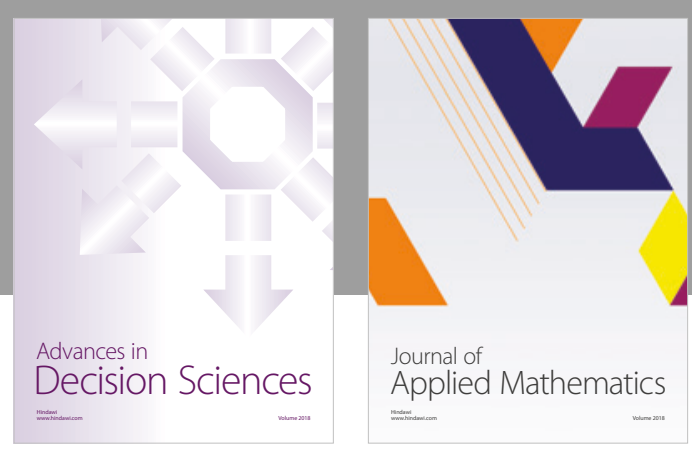

Journal of

Applied Mathematics
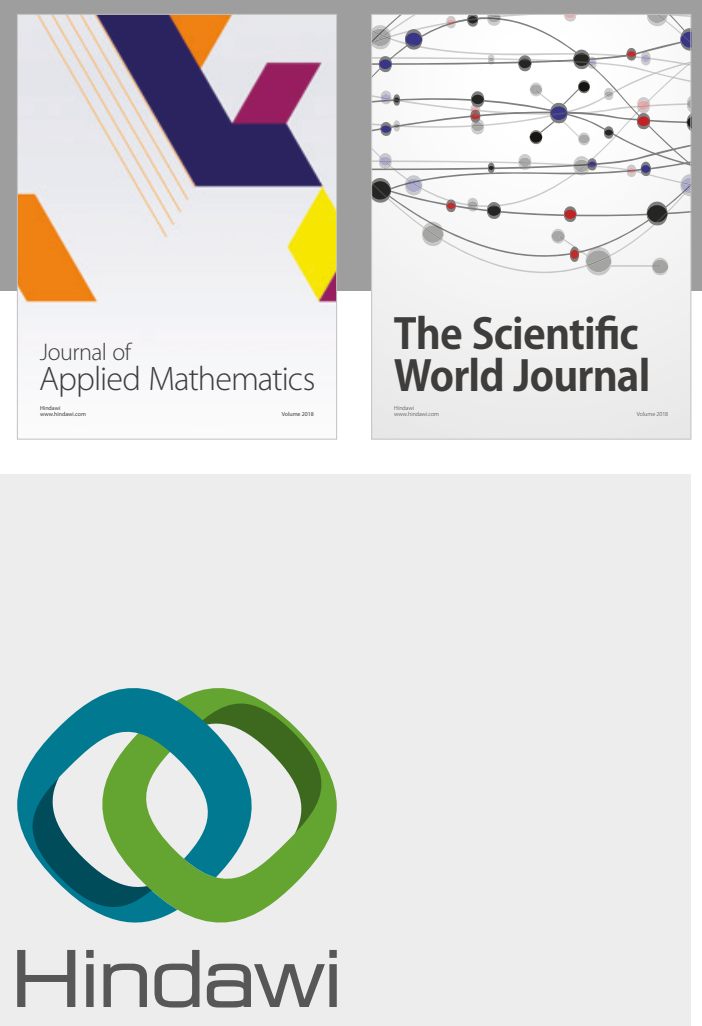

Submit your manuscripts at

www.hindawi.com

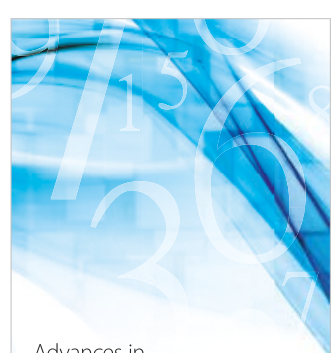

Advances in
Numerical Analysis
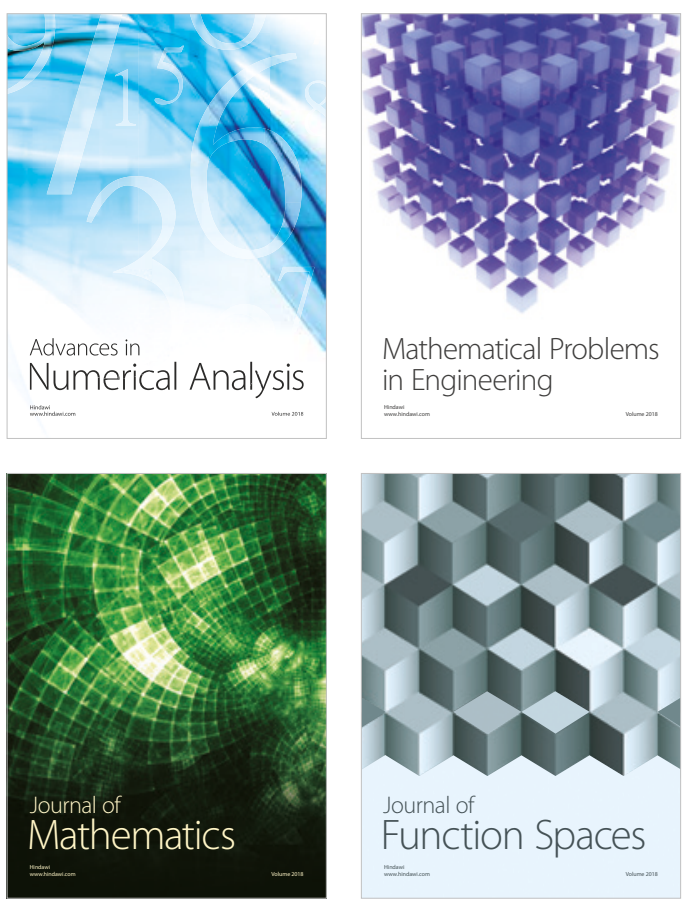

Mathematical Problems in Engineering

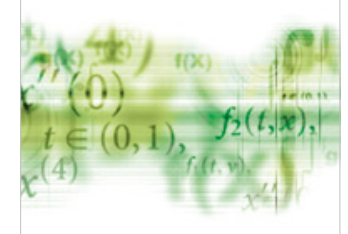

International Journal of

Differential Equations

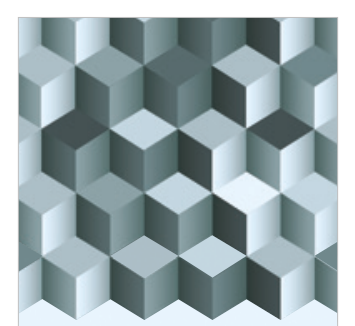

Journal of

Function Spaces

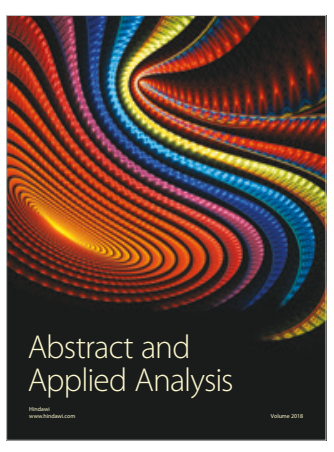

The Scientific

World Journal

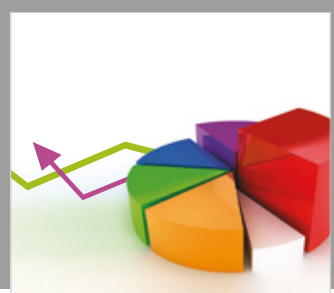

Journal of

Probability and Statistics
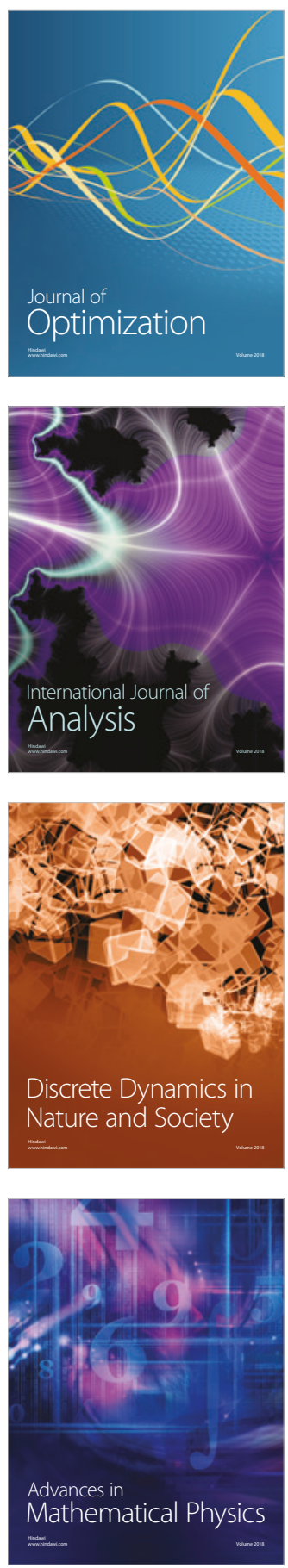